$\mathbb{T}$ periodica polytechnica

Civil Engineering

$56 / 2(2012) 175+183$

doi: 10.3311/pp.ci.2012-2.04

web: http://www.pp.bme.hu/ci

(c) Periodica Polytechnica 2012

RESEARCH ARTICLE

\section{Effect of corrosion on the buckling of steel angle members - experimental study}

\author{
Katalin Oszvald / László Dunai
}

Received 2011-07-15, revised 2011-11-10, accepted 2012-10-15

\begin{abstract}
The aim of this work is to study the effect of corrosion on the buckling behaviour and resistance of corroded steel angle section members. The influences of the corrosion location and the loss of cross-section are studied by experimental investigations, where the corrosion is modelled by artificial thickness reduction. Compressive buckling tests are carried out on twenty-four specimens. Different corrosion damages are modelled, like uniform, pitting and local corrosion in the specimens. The buckling behaviour and the relationship of the corrosion reduction and the resistance decrease are determined.
\end{abstract}

\section{Katalin Oszvald}

Budapest University of Technology and Economics, Department of Structural Engineering, H-1111 Budapest, Múegyetem rkp. 3, Hungary

e-mail: oszvaldkata@gmail.com

\section{László Dunai}

Budapest University of Technology and Economics, Department of Structural Engineering, H-1111 Budapest, Múegyetem rkp. 3, Hungary

\section{Introduction}

\subsection{General}

Every structure is exposed to the influence of different environment and tends to suffer various types of damage as they get older. The steel structures such as truss bridges, transmission line towers and other structures can be corroded significantly, because of the different aggressive environmental and weather circumstances and due to the inadequate maintenance. Recently several bridges in Hungary had to be repaired due to the damages caused by corrosion. In the case of the Margaret Bridge in Budapest, the inadequate maintenance caused serious corrosion; several members of the stiffener frame/bracing system corroded, as shown in Fig. 1(a). In the case of Liberty Bridge - another Danube bridge of Budapest - the corrosion caused big loss of cross-section, leading to failure of a compression member, as it is illustrated in Fig. 1 (b). Note that the corroded member shown in the figure was made of wrought steel.
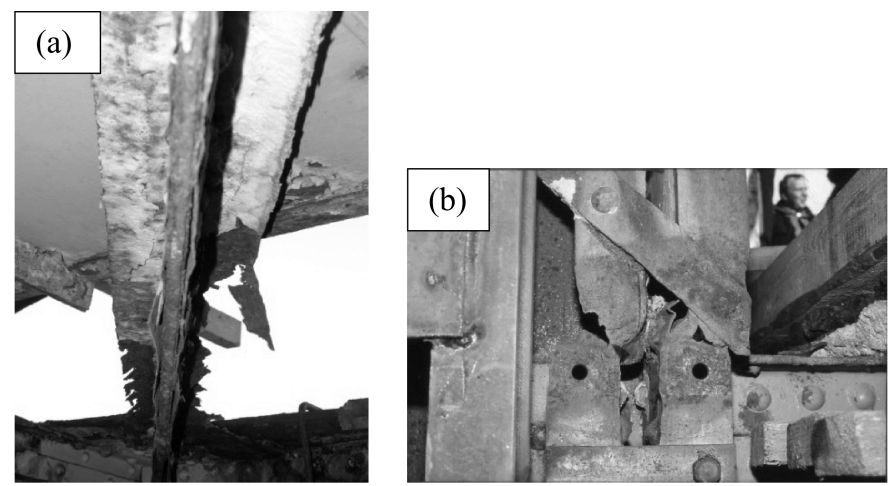

Fig. 1. Corroded structural details in (a) Margaret Bridge and (b) Liberty Bridge

Corrosion can be observed in different places and sizes of the corroded members. During the reparation of the bridge structures it is essential to determine the behaviour and resistance reduction of these members. It is also necessary to decide, that the corroded members have to be replaced or can be strengthened. The codes and standards usually do not give detailed suggestion how the corroded members, connections and structures can be assessed. Eurocode 3 [1] and other major standards such as CAN/CSA, AISC, ASCE recommend to apply average cross- 
section reduction [2] in the prediction of the resistance. Because of the lacking of detailed instructions it may be complicated to estimate the decrease of the resistance of a corrosion damaged member, especially if the damage is not uniform along the member. The corrosion can lead to significant thickness reduction and change in cross-section classification [1], therefore ultimate behaviour can be complicated as typical in thin-walled structural elements [3].

\subsection{Previous studies}

Appearance, level and location of corrosion may be very different in structures, therefore these effects are widely studied. Beaulieu et al. [2] investigated steel angle members corroded by galvanic process. The main studied parameters in this work were the slenderness, the width-to-thickness ratio and the level of corrosion means cross-section reduction. The specimens were experimentally investigated in truss structure under eccentric compression. The failure modes and the compressive resistance were determined and compared to analytical results. In addition several other studies were completed on the effect of corrosion what proves the importance of the subject and not only in civil engineering structures. Researchers investigated e.g. corroded beams [4], sheared plates [5], compressed plates [6] and pitting corrosion in ships [7]. In these studies the resistance reduction and the ultimate behaviour of the corroded members were determined. The connections, the bolts and rivets also can be corroded; in [8] the durability of the corroded connection is examined. In the previous studies the different types and location of corrosion are not investigated on corroded angle members, what is the subject of the current research.

\subsection{Purpose and scope}

The experimental work detailed in this paper focuses on the stability behaviour and the compressive buckling resistance of corroded angle members. The aim is to find the tendencies of the effect of different location and size of corrosion on the buckling phenomenon and resistance. The changes in the resistance of various cases are studied. It is planned to determine the local and the global failure modes as well as the post-buckling yield mechanism on the corroded members. The corrosion is considered by loss of cross-section applying artificial thickness reduction. The behaviour and the resistance of the corroded members are compared to the reference non-corroded members and standard based design resistances.

\section{Experimental program}

\subsection{Specimens and test set-up}

Compressive buckling tests are carried out on 24 steel angle section specimens, where the corrosion is modelled by artificial reduction of thickness in the legs by milling process. The size of the section of the specimens is $40 \times 40 \times 4 \mathrm{~mm}$, while the length of the member is $790 \mathrm{~mm}$. The sizes of the members are selected to study the buckling behaviour of the member resulting in a 1.25 non-dimensional slenderness. In the specimens different corrosion locations and material loss ratios are applied. The tests are divided into three groups according to the modelled corrosion: uniform, pitting and local. In addition, two specimens $(\mathrm{O} 1, \mathrm{O} 2)$ without damages are investigated and are referred as original or non-corroded members. The details of the corroded specimens with the modelled corrosion locations and the shapes are summarised in Tables 2, 4. The corroded areas are marked with black colour.

In several experimental studies [7, 9] the corrosion is modelled as a thickness reduction and parts of the member or the thickness were eliminated artificially. In numerical investigations also used thickness reduction for modelling the effect of corrosion [4-6]. In the applied milling process the machine has got a spinning mill head and this process does not change the material properties of the steel member.

The $t_{\text {corr }}$ means the thickness of the corrosion. The effective specimen dimensions and the thickness of the members are measured on each leg at ten locations with mortise gauge. The $A_{\text {corr }}$ characteristic is introduced as the average corrosion volume reduction; it is calculated as the ratio of the corroded volume comparing to the total original volume of the specimen. The maximal cross-section reduction $\left(M_{\text {corr }}\right)$ is interpreted as the ratio of the maximal cross-section reduction in the member compared to the gross area. $A_{\text {corr }}$ and $M_{\text {corr }}$ values are calculated on the basis of the measured dimensions and detailed in Tables 24.

The cross-section is classified by the width-to-thickness (b/t) ratio of the legs according to Eurocode 3 . In the case of the noncorroded members the class of the cross-sections is (the $b / t$ ratio is 10). The class of the cross-section of all corroded members is 4 (with different $b / t$ ratios).

Tensile coupon tests are carried out to determine the material properties of the specimens. The measured average material properties of three tests are shown in Table 1 Material I and II mark the two different materials applied in the specimens. These codes are shown in parentheses after the identification of the specimen in Tables 24

Tab. 1. Material properties

\begin{tabular}{ccc}
\hline Material & $\mathrm{f}_{\mathrm{y}}\left[\mathrm{N} / \mathrm{mm}^{2}\right]$ & $\mathrm{f}_{\mathrm{u}}\left[\mathrm{N} / \mathrm{mm}^{2}\right]$ \\
\hline $\mathrm{I}$ & 335 & 460 \\
\hline II & 357 & 475 \\
\hline
\end{tabular}

In the test set-up the support is hinge connection in the centre of gravity of the cross-section. Bearing ball is applied on the end-plate of the specimen in the test arrangement. The support is always applied in the centre of gravity of the original, non-corroded cross-section, with some random, unavoidable eccentricities. The differences between the original and corroded cross-section result in further eccentricity in the loading of the corroded members. Load cell is applied to measure the load and the horizontal and vertical displacements are measured by pulley systems with displacement transducers between the head of the 

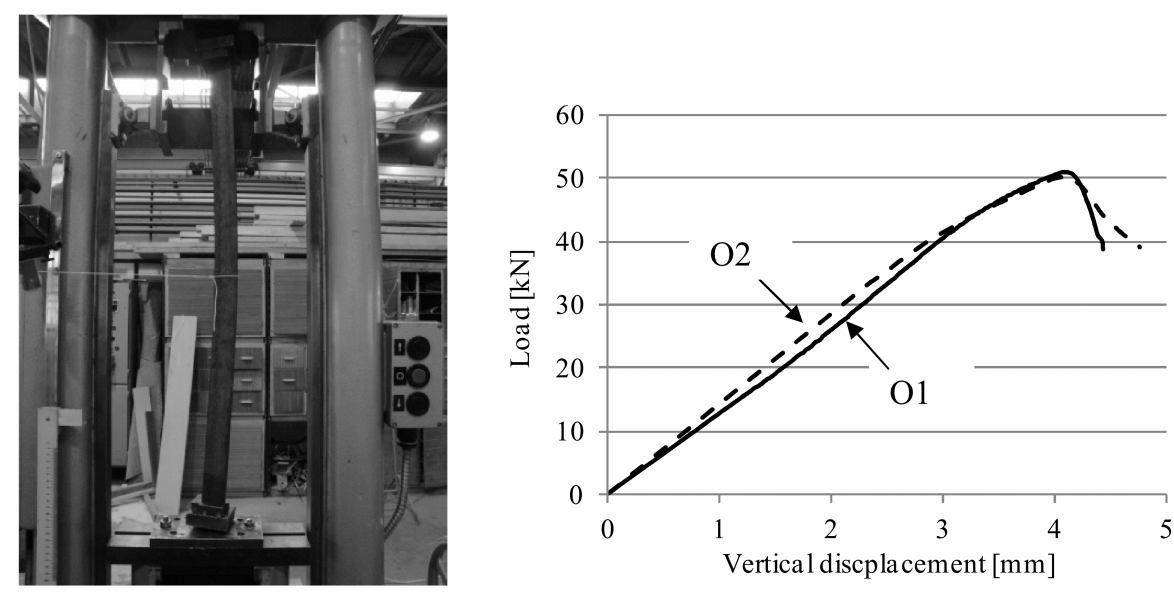

Fig. 2. Test setup and global failure mode; load - displacement curves

loading machine and in the half of the member length, respectively. More details on the measurement system can be found in [10].

\subsection{Uniform corrosion specimens}

In the case of uniform corrosion the same cross-section reduction is applied along the length of the specimen (total or partial length). Members of this group are signed from A1 to A11 in Table 2. Specimen A1 is the basic case: both of legs are reduced along the whole length. Different corrosion positions are applied within the cross-section with similar volume reduction $\left(A_{\text {corr }}\right)$ in A 2 - A6 members. In A7 - A 8 specimens the effect of corrosion on the edges and in the middle of the members are analysed; the corroded surface and $A_{\text {corr }}$ are similar to A2 - A6 specimens but the $M_{\text {corr }}$ value is different. In A9 - A11 members different corrosion arrangements in both legs along the length are applied with the same $A_{\text {corr }}$ value.

\subsection{Pitting corrosion specimens}

Specimens P1 - P4 model the pitting corrosion as shown in Table 3 In this case the $t_{\text {corr }}$ parameter means the depth of the pits. In the formation of the corrosion pattern the experiences of previous studies are applied [7,9], with two different pit diameters: $\mathrm{d}_{1}=12 \mathrm{~mm}$ and $\mathrm{d}_{2}=25 \mathrm{~mm}$.

\subsection{Local corrosion specimens}

Table 4 contains the members with localized, highly corroded cross-section reduction, with lower $A_{\text {corr }}$ and higher $M_{\text {corr }}$ values comparing to the A type specimens. Specimens L1 - L3 are applied to observe the effect of the local corrosion position along the member. In L1, L4 and L5 members $A_{\text {corr }}$ are the same with different $M_{\text {corr }}$ ratios. L6 and L1 specimens are identical, but in L6 significant initial imperfections are applied. The thickness reduction in specimen $\mathrm{L} 7$ is changing along the element; the biggest thickness decrease is $80 \%$ in one of the legs at the edge and the maximal cross-section reduction is approximately $50 \%$.

\section{Experimental behaviour}

The non-corroded members give the base of comparison in behaviour. In the followings first the ultimate failure mode of the non-corroded and then the corroded members are discussed.

\subsection{Non-corroded members}

In the case of $\mathrm{O} 1$ and $\mathrm{O} 2$ members the observed failure mode is global flexural buckling about the weak axis. The yield mechanism is developed at the half-length of the member according to the expectation. In Fig. 2 the test setup and failure mode can be seen, together with the load - vertical displacement curves regarding to $\mathrm{O} 1$ and $\mathrm{O} 2$ non-corroded members. In case of $\mathrm{O} 1$ member the design buckling resistance is $40.18 \mathrm{kN}$ and in case of $\mathrm{O} 2$ member it is $40.76 \mathrm{kN}$, according to Eurocode 3 design method.

\subsection{Uniform corrosion specimens}

In the case of uniform corroded members the same failure mode, flexural buckling is observed, as in the case of noncorroded cases. As a typical example, the load - horizontal displacement curve of A10 specimen is shown in Fig. 3. The shape of the curve is similar to the original members having smaller ultimate load of the corroded specimen.

\subsection{Pitting corrosion specimens}

The pitting corrosion members had also global buckling mode. The effect of the whole-length uniform and the pitting corrosion on the behaviour is similar. The load - horizontal displacement curve of P1 specimen is illustrated in Fig. 3. Note that the initial stiffness is bigger in this specimen, what can be explained by the smaller, randomly resulted eccentricity.

\subsection{Local corrosion specimens}

The failure mode of the specimens with local corrosion is either global flexural buckling or local buckling in the reduced cross-section part of the member. The local buckling occurred in all cases in one leg. In several cases after reaching the 
Tab. 2. Uniform corrosion specimens

\begin{tabular}{|c|c|c|c|c|c|}
\hline Specimen & Location of corrosion & $\mathrm{t}_{\text {corr }}$ & $\mathrm{A}_{\text {corr }}[\%]$ & $\mathrm{M}_{\text {corr }}[\%]$ & $b / t$ \\
\hline Al (I) & & $1 \mathrm{~mm}$ & 29.0 & 29.0 & 13.3 \\
\hline A2 (I) & & $1 \mathrm{~mm}$ & 12.8 & 12.8 & 13.3 \\
\hline A3 (I) & & $1 \mathrm{~mm}$ & 11.7 & 11.7 & 13.3 \\
\hline A4 (I) & & $1 \mathrm{~mm}$ & 14.7 & 14.7 & 13.3 \\
\hline A5 (I) & & $1 \mathrm{~mm}$ & 12.7 & 12.7 & 13.3 \\
\hline A6 (I) & & $1 \mathrm{~mm}$ & 18.8 & 18.8 & 13.3 \\
\hline A7 (I) & & $1 \mathrm{~mm}$ & 12.4 & 25 & 13.3 \\
\hline A8 (I) & & $1 \mathrm{~mm}$ & 11.8 & 25 & 13.3 \\
\hline A9 (II) & & $1 \mathrm{~mm}$ & 13 & 13 & 13.3 \\
\hline A10 (II) & 395 & $1 \mathrm{~mm}$ & 13 & 13 & 13.3 \\
\hline A11 (II) & & $1 \mathrm{~mm}$ & 13 & 13 & 13.3 \\
\hline
\end{tabular}

Tab. 3. Pitting corrosion specimens

\begin{tabular}{|c|c|c|c|c|c|c|}
\hline Specimen & & Location of corrosion & & $t_{\text {corr }}$ & $\mathrm{A}_{\text {corr }}[\%]$ & $\mathrm{M}_{\text {corr }}[\%]$ \\
\hline P1 (II) & 1 & 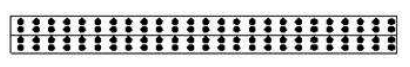 & $\mathrm{d}_{1}$ & $2 \mathrm{~mm}$ & 9 & 31.3 \\
\hline P2 (II) & & 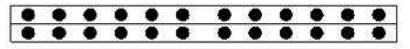 & $d_{2}$ & $2 \mathrm{~mm}$ & 9 & 32.6 \\
\hline P3 (II) & i & 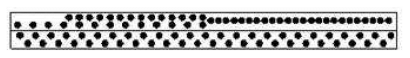 & $\mathrm{d}_{1}$ & $2 \mathrm{~mm}$ & 9 & 23.4 \\
\hline P4 (II) & & $\because \div 00 \div 0$ & $\mathrm{~d}_{2}$ & $2 \mathrm{~mm}$ & 9 & 32.6 \\
\hline
\end{tabular}

Tab. 4. Local corrosion specimens

\begin{tabular}{|c|c|c|c|c|c|}
\hline Specimen & Location of corrosion & $\mathrm{t}_{\text {corr }}$ & $\mathrm{A}_{\text {corr }}[\%]$ & $\mathrm{M}_{\text {corr }}[\%]$ & $b / t$ \\
\hline L1 (II) & 100 & $3 \mathrm{~mm}$ & 8.3 & 70 & 40 \\
\hline L2 (II) & $\downarrow 205|100|$ & $3 \mathrm{~mm}$ & 8.7 & 73.5 & 40 \\
\hline L3 (II) & \begin{tabular}{|l|} 
\\
$65 \nmid 100 \nmid$ \\
65
\end{tabular} & $3 \mathrm{~mm}$ & 9.0 & 76 & 40 \\
\hline L4 (II) & $\begin{array}{r}320 \\
+\quad \\
\end{array}$ & $2 \mathrm{~mm}$ & 8.9 & 49.8 & 20 \\
\hline L5 (II) & $\begin{array}{l} \\
\downarrow \quad 245 \\
\end{array}$ & $1 \mathrm{~mm}$ & 9.9 & 27.8 & 13.3 \\
\hline L6 (II) & 345 & $3 \mathrm{~mm}$ & 8.6 & 73 & 40 \\
\hline L7 (II) & 100 & $1 \mathrm{~mm}$ & 23.1 & 50 & 40 \\
\hline
\end{tabular}

load-bearing capacity the post-buckling branch of the loaddisplacement curves shows increasing tendency after a sudden jump in the strength. Figure 4 shows the buckling shape of L1 specimen and the load - horizontal displacement curves of L1 L3 specimens
Investigating the effect of corrosion positions of L1 - L3, the same buckling behaviour is observed. The character of the load - horizontal displacement curves is the same, as it is illustrated in Fig. 4, decreasing in degree of hardening is observed, when the position is come closer to the end of member. By investigat- 


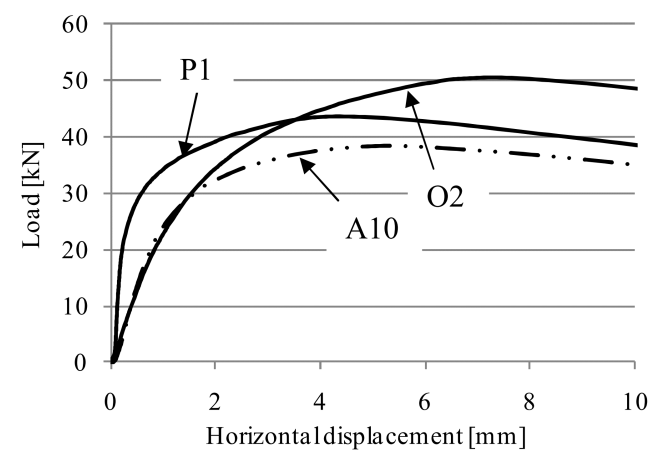

Fig. 3. Load - displacement curves of $\mathrm{O} 2, \mathrm{P} 1$ and $\mathrm{A} 10$ specimens
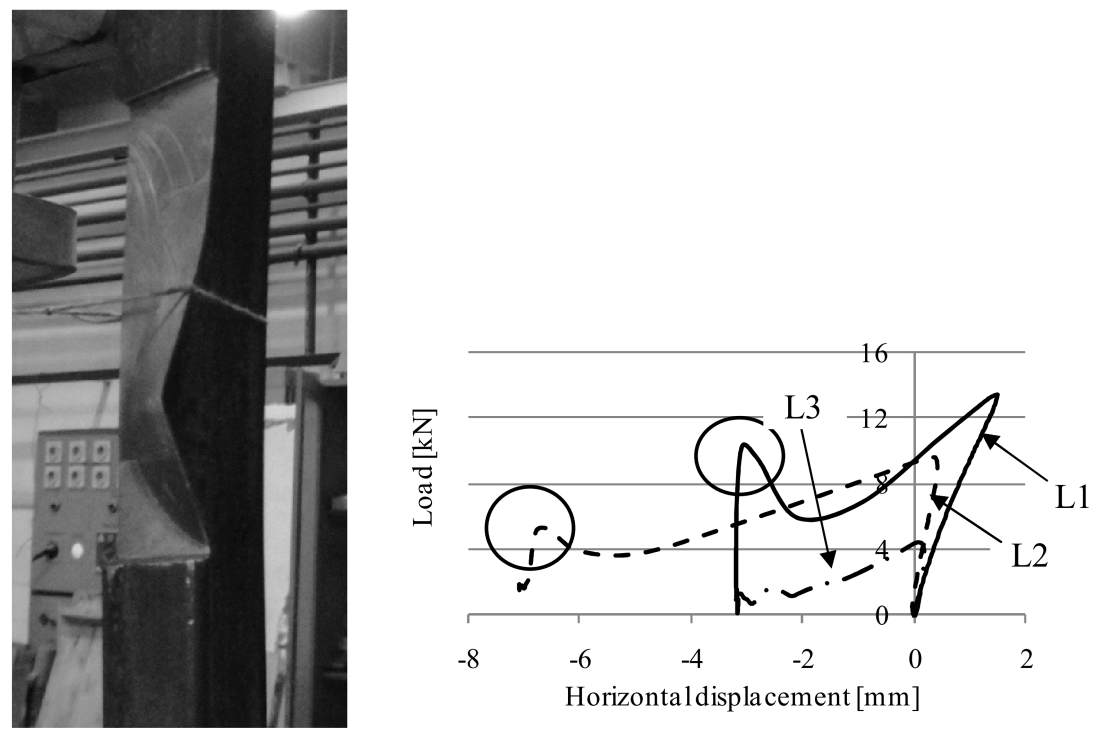

Fig. 4. Local failure mode; load - displacement curves

ing the effect of extension of corroded surface (L1, L4, L5), the same initial behaviour are observed as it is shown on the load - horizontal displacement curves in Fig. 5 The ultimate failure mode is local buckling in L1 specimen and global buckling in L4 - L5 specimens.

Same failure mode and different initial behaviour are observed in the cases of specimens L1 and L6. L1 specimen shows initial global behaviour while L6 shows local phenomenon. Differences are observed in the buckling mode, the load level and the load - displacement curve. As it is expected the corroded specimen with higher initial imperfection (L6) significantly deteriorate the buckling behaviour. In specimen L7 the maximal cross-section reduction is lower than in L6, but approximately the same as in L4. The failure mode of L7 is the same local plate buckling as for L6, since one of the legs has about $80 \%$ thickness reduction. The similarity between L6 and L7 also can be observed by comparison the load - horizontal displacement curves and the buckling modes, as shown in Fig. 6

\section{Measured buckling resistances}

The experimental buckling resistances of the members are interpreted as the plateau of the load - displacement curve. The buckling resistance values are presented in Tables 5,8 The ta- bles contain the measured resistance results $\left(\mathrm{N}_{b, m}\right)$ and the ratio of the $\mathrm{N}_{b, m}$ and $\mathrm{N}_{c}$, where compressive strength $\mathrm{N}_{c}$ is calculated by the maximal corroded cross-section area $\mathrm{A}_{c}$ of each members according to the Eurocode 3, Eq. (1).

$$
N_{c}=A_{c} \cdot f_{y}
$$

Tables 54 contain the ratio of the $N_{b, m}$ and $N_{b 0, m}$, where $N_{b 0, m}$ denotes the measured resistance of the non-corroded members. The measured resistances of the non-corroded members and the calculated ratios are given in Table 5

Tab. 5. Results of the tests - non-corroded members

\begin{tabular}{cccc}
\hline Specimen & $\begin{array}{c}\mathrm{N}_{\mathrm{b}, \mathrm{m}} \\
{[\mathrm{kN}]}\end{array}$ & $\mathrm{N}_{\mathrm{b}, \mathrm{m}} / \mathrm{N}_{\mathrm{b} 0, \mathrm{~m}}$ & $\mathrm{~N}_{\mathrm{b}, \mathrm{m}} / \mathrm{N}_{\mathrm{c}}$ \\
\hline $\mathrm{O} 1$ & 50.65 & 1.00 & 0.49 \\
\hline $\mathrm{O} 2$ & 50.33 & 1.00 & 0.45 \\
\hline
\end{tabular}

\subsection{Uniform specimens}

In Table 6 the measured resistances and the calculated ratios of the uniform corroded specimens are detailed. The resistances show significant scatter. Note that in the cases of A2 and A4 elements no resistance decrease is experienced; it can be explained 


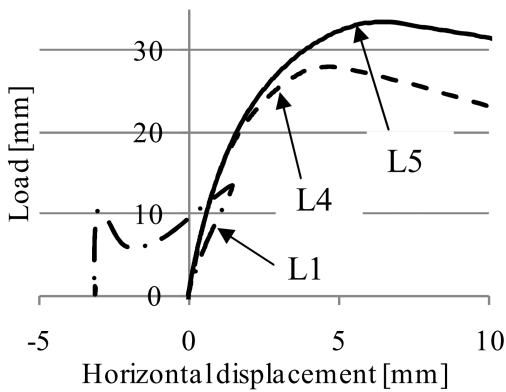

Fig. 5. Load - displacement curves of local corrosion specimens
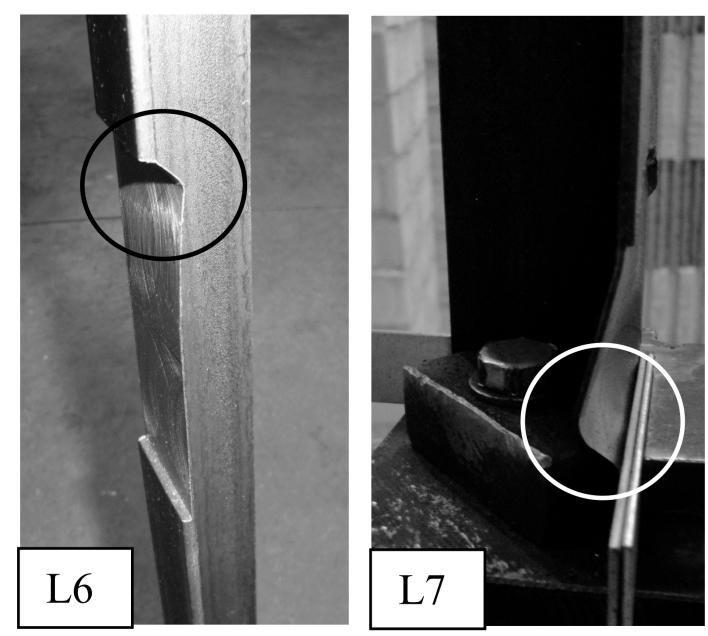

Fig. 6. Local buckling modes

by the random eccentricities end restraints of the specimens. In this group A1 member has the maximal $A_{c o r r}$ value (biggest volume decrease) and this member gives the lowest bound in the evaluations.

On the basis of measured resistances the following observations are made:

- Corrosion on the inner side of the leg (A3) causes bigger resistance reduction, than corrosion on the outer side (A2).

- The specimens A4 - A6 have same corroded surface on different parts of the legs. Corrosion position on the inner part of the legs with symmetrical arrangement (A5) causes approximately $30 \%$ resistance decreasing compared to the noncorroded member. This is significantly different from A4 specimen where the corrosion is on the outer part of the legs and the reduction of the resistance is almost negligible. Unsymmetrical corrosion pattern (A6) causes even more reduction in buckling resistance $(\sim 33 \%)$.

- Corrosion in the middle of the specimen (A8) causes bigger decrease in buckling resistance compared to corrosion close to the supports (A7). The difference is about $10 \%$ compared to the non-corroded members.

- A9 - A11 have the same corroded surface with different positions in the specimens. When corrosion is only on one of the legs (A9), the buckling resistance value is bigger, compared to the corrosion on both of the legs. When corrosion

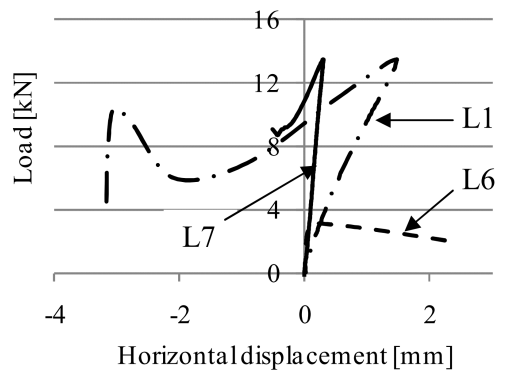

less continuous the buckling resistance decrease is bigger, as it is observed in A10 and A11 specimens.

\subsection{Pitting corrosion specimens}

Table 7 shows the measured and calculated results of the pitting corroded members. The following observation can be done on the basis of the results:

\subsection{Local corrosion specimens}

Table 8 contains the results of local specimens. Based on the result the following observations can be done:

- Corrosion position in the middle of the specimen (L1) causes smaller decreasing in buckling resistance, than corrosion location near to the support (L3). The cross-section reduction in these cases more than $50 \%$, and the governing behaviour is local buckling.

- The tendency of the reduction of resistance is approximately linear as the position is closer to the support.

The following observation can be done when specimens have a same volume reduction $\left(\mathrm{A}_{\text {corr }}\right)$ and different cross-section reduction $\left(\mathrm{M}_{\text {corr }}\right)$ :

- Widely spread corroded surface with small cross-section reduction (L5) causes lower reduction in resistance compared to localized corrosion with bigger cross-section value (L4). 
Tab. 6. Results of the tests - uniform corrosion

\begin{tabular}{|c|c|c|c|c|}
\hline Specimen & Location of corrosion & $\mathrm{N}_{\mathrm{b}, \mathrm{m}}[\mathrm{kN}]$ & $\mathrm{N}_{\mathrm{b}, \mathrm{m}} / \mathrm{N}_{\mathrm{b} 0, \mathrm{~m}}$ & $\mathrm{~N}_{\mathrm{b}, \mathrm{m}} / \mathrm{N}_{\mathrm{c}}$ \\
\hline A1 & & 33.2 & 0.66 & 0.45 \\
\hline $\mathrm{A} 2$ & & 51.02 & 1.00 & 0.56 \\
\hline $\mathrm{A} 3$ & & 41 & 0.81 & 0.45 \\
\hline A4 & & 50.95 & 1.00 & 0.57 \\
\hline A5 & & 35.5 & 0.70 & 0.39 \\
\hline A6 & & 33.6 & 0.67 & 0.40 \\
\hline A7 & & 43.8 & 0.87 & 0.56 \\
\hline A8 & & 37.7 & 0.75 & 0.48 \\
\hline A9 & & 43.68 & 0.87 & 0.45 \\
\hline A10 & 395 & 38.5 & 0.76 & 0.40 \\
\hline A11 & 200 & 36.93 & 0.73 & 0.38 \\
\hline
\end{tabular}

Tab. 7. Results of the tests - pitting corrosion

\begin{tabular}{|c|c|c|c|c|}
\hline Specimen & Location of corrosion & $\mathrm{N}_{\mathrm{b}, \mathrm{m}}[\mathrm{kN}]$ & $\mathrm{N}_{\mathrm{b}, \mathrm{m}} / \mathrm{N}_{\mathrm{b} 0, \mathrm{~m}}$ & $\mathrm{~N}_{\mathrm{b}, \mathrm{m}} / \mathrm{N}_{\mathrm{c}}$ \\
\hline $\mathrm{P} 1$ & 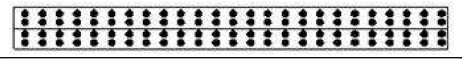 & 44.72 & 0.89 & 0.59 \\
\hline P2 & $:::::::::::::::$ & 49.23 & 0.98 & 0.66 \\
\hline P3 & 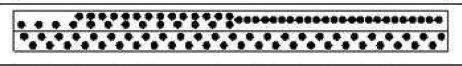 & 47.16 & 0.93 & 0.55 \\
\hline P4 & $\because \because \bullet \bullet \bullet \circ \div \div$ & 49.6 & 0.98 & 0.66 \\
\hline
\end{tabular}

- The tendency is not linear in decreasing; when the specimen has local buckling behaviour, the value of the decrease is bigger. The tendency is shown by the $\mathrm{N}_{b, m} / \mathrm{N}_{b 0, m}$ ratio.

- The effect of initial imperfection is shown by the comparison of L1 and L6 specimens; the increased initial imperfection causes lower buckling resistance $(\sim 20 \%)$.

\section{Evaluation of resistances}

The experimental results of the specimens in three groups are evaluated in this chapter jointly. Figure 7 presents the resistance results plotted in the function of volume reduction $\left(A_{\text {corr }}\right)$. The mean resistance value is $28.5 \mathrm{kN}$ and the standard deviation is $66 \%$ in members with $9 \%$ average cross-section reduction. In the case of specimens with $\sim 13 \% A_{\text {corr }}$ the mean value of the resistances is $40.1 \mathrm{kN}$ and the standard deviation is $13.3 \%$. In the first case the locally corroded members cause the significant scatter, whereas the maximal cross-section decrease is high but the average cross-section decrease is much smaller compared to the uniform specimens. Disregarding locally corroded members the difference in resistance is smaller, but even the maximal decrease is $28 \%$ (A11) comparing to the original members. This observation shows that the estimation of the resistance by average cross-section might be uncertain and the $A_{\text {corr }}$ parameter alone is not reliable to determine the resistance reduction.

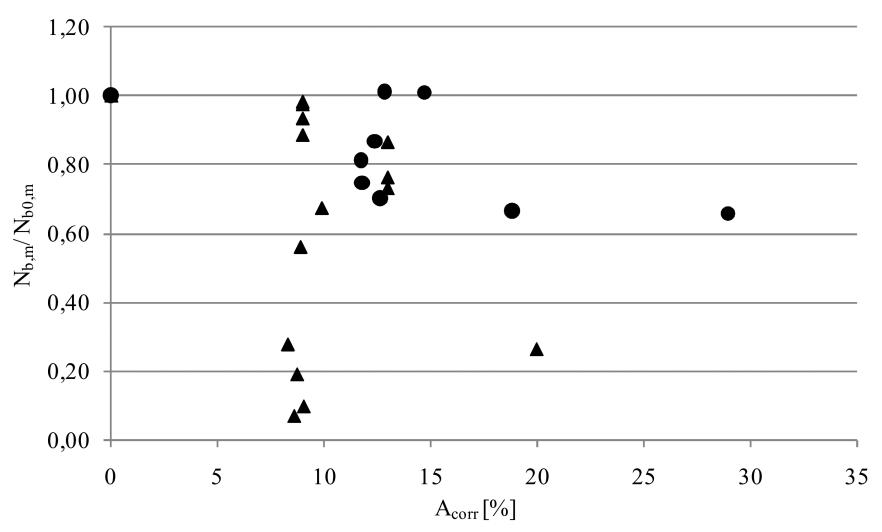

Fig. 7. Experimental results in the function of average cross-section reduction $\left(\bullet f_{y}=335 \mathrm{~N} / \mathrm{mm}^{2} ; \boldsymbol{\Delta} f_{y}=357 \mathrm{~N} / \mathrm{mm}^{2}\right)$

The buckling resistance is compared to the maximal crosssection reduction $\left(M_{\text {corr }}\right)$ in Fig. 8. The continuous line mark equivalent decrease in resistance and in cross-section reduction. The measured results are on both side of the line. There is no regularity observed in the resistance values. The determined equivalent resistance decrease is not acceptable, particularly in case of the localized corroded members with large discrete cross-section reduction. Application of a maximal crosssection is a better approach than the average cross-section reduction, because the effect of local corrosion is reduced. Despite it 
Tab. 8. Results of the tests - local corrosion

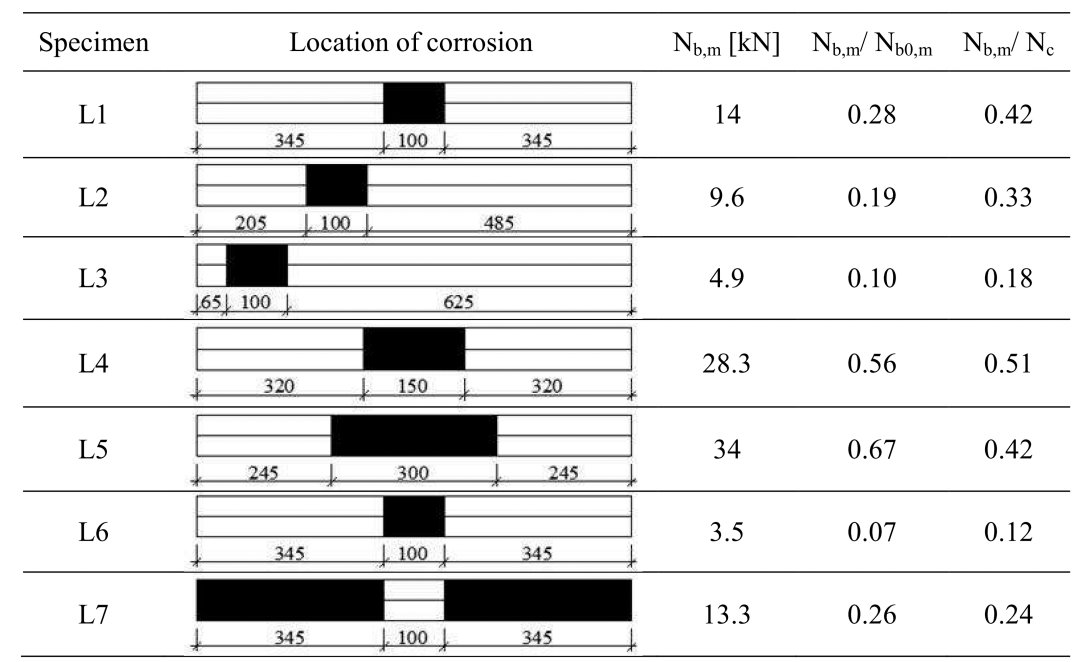

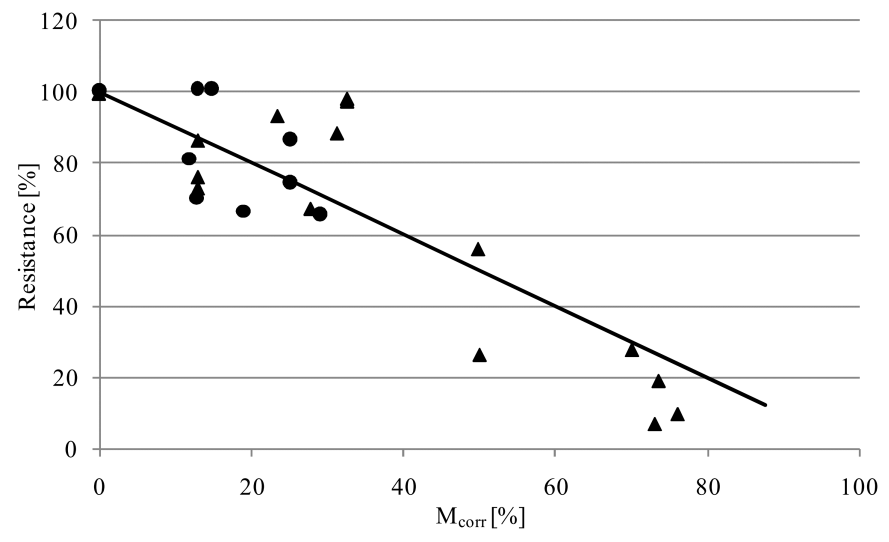

Fig. 8. Resistance and maximal cross-section reduction $\left(\bullet f_{y}=335 \mathrm{~N} / \mathrm{mm}^{2}\right.$; $\Delta f_{y}=357 \mathrm{~N} / \mathrm{mm}^{2}$ )

is evident from the diagram that this parameter cannot be used as a governing parameter of the resistance reduction.

In the next step of the evaluation the design buckling resistance of compression member is calculated according to Eurocode 3, as shown in Eq. 22. The thickness reduction is supposed to be $1,2,3$ and $3.5 \mathrm{~mm}$ on both of the member legs along the length. Effective characteristics of cross-section are applied to determine the buckling resistance. The broken line shows the results of buckling resistance according to Eurocode 3 in Fig. 9, and Table 9 shows the details of the calculation.

$$
N_{b, R d}=\chi \frac{A \cdot f_{y}}{\gamma_{M 1}}
$$

Almost every case, except the pitting corroded members, the corrosion causes changing in the classification of the crosssection. Therefore in the design buckling resistance calculation the effective cross-section is used, along the whole length. In Fig. 9 results are plotted in the function of $M_{\text {corr }}$ and $A_{\text {corr }}$. Estimating the buckling resistances of corroded members by the Eurocode 3 it can be seen that the results are in the safe range in every case if the basis of comparison is $M_{c o r r}$. In some cases the estimation too conservative, e.g. for L5 the measured buckling resistance is $28.3 \mathrm{kN}$, but the code the estimation gives $12.1 \mathrm{kN}$. If the results are evaluated by $A_{\text {corr }}$ in the cases of locally corroded members the measured buckling resistances are smaller than the estimated. However in other cases e.g. for A9 specimen the estimation is also conservative as in the previous case. According to the tests the $M_{\text {corr }}$ can be proposed for the estimation of the buckling resistance as a conservative approach.

From the above evaluation of the results it can be concluded that the complex buckling phenomena of the corroded angle members can be described by many parameters, as cross-section reduction, volume decrease, position of corrosion and extension. The completed tests show the tendencies of the behaviour but not enough to derive practically applicable design recommendations.

\section{Summary and conclusions}

In the research corroded compressed angle sections are studied. Buckling tests are carried out on 24 steel angle section specimens, where the corrosion is modelled by the artificial loss of cross-section in different locations. Uniform, pitting and local corrosions are modelled. The resistance and the behaviour of the steel angle section members are determined and evaluated. On the basis of the experimental study the following conclusions can be made:

- The buckling resistance is reduced by corrosion in different rate: different corrosion position, cross-section and volume reduction causes large scatter in the buckling resistance reduction. The governing buckling mode is global flexural buckling for uniform and pitting corrosion specimens and local plate buckling for locally corroded specimens in the investigated cases.

- Eurocode 3 method for buckling resistance prediction can be used as a conservative estimation by applying the maximal cross-section reduction along the member, considering the changing of the cross-section class due to the decreased thickness. 
Tab. 9. Design buckling resistances

\begin{tabular}{|c|c|c|c|c|c|c|}
\hline $\begin{array}{c}\text { Thickness } \\
\text { reduction } \\
{[\mathrm{mm}]}\end{array}$ & \multicolumn{2}{|c|}{$\begin{array}{c}\text { Cross-section reduction } \\
{[\%]}\end{array}$} & $\mathrm{L}[\mathrm{mm}]$ & $\begin{array}{c}\mathrm{A}\left(\mathrm{A}_{\mathrm{eff} f}\right) \\
{\left[\mathrm{mm}^{2}\right]}\end{array}$ & $\chi$ & $\mathrm{N}_{\mathrm{b}, \mathrm{Rd}}[\mathrm{kN}]$ \\
\hline 0 & & & 840 & 308 & 0,38 & 38,7 \\
\hline 1 & \multirow{4}{*}{ 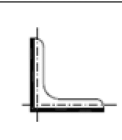 } & 25 & 840 & 226 & 0,37 & 28,3 \\
\hline 2 & & 50 & 840 & 128,3 & 0,28 & 12,1 \\
\hline 3 & & 75 & 840 & 42,94 & 0,13 & 1,9 \\
\hline 3,5 & & 87,5 & 840 & 15,4 & 0,06 & 0,31 \\
\hline
\end{tabular}
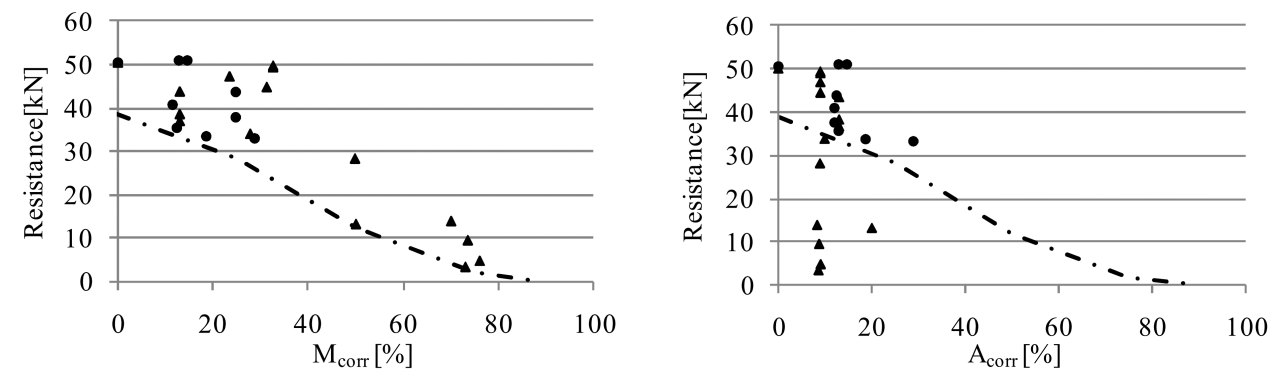

Fig. 9. Experimental vs. design buckling resistance $\left(\bullet f_{y}=335 \mathrm{~N} / \mathrm{mm}^{2} ; \boldsymbol{\Delta} f_{y}=357 \mathrm{~N} / \mathrm{mm}^{2}\right)$

- The experimental study is used as a background of a further study by developing advanced numerical model and extending the test results by virtual experiments [11].

\section{Acknowledgement}

This work is connected to the scientific program of the "Development of quality-oriented and harmonized $\mathrm{R}+\mathrm{D}+\mathrm{I}$ strategy and functional model at BME" project. This project is supported by the New Hungary Development Plan (Project ID: TÁMOP4.2.1/B-09/1/KMR-2010-0002).

\section{References}

1 EN 1993-1-1: Design of steel structures. Part 1-1: General rules and rules for buildings, 2005.

2 Beaulieu L., Legeron F, Langlois S, Compression strength of corroded steel angle members, Journal of Constructional Steel Research 66 (2010), no. 11, 1366-1373, DOI 10.1016/j.jcsr.2010.05.006.

3 Joó A., Ádány S, FEM-based approach for the stability design of thinwalled members by using cFSM base functions, Periodica Polytechnica in Civil Engineering 52 (2009), no. 2, 61-74, DOI 10.3311/pp.ci.2009-2.02.

4 Rehgozar R, Remaining capacity assessment of corrosion damaged beams using minimum curves, Journal of Constructional Steel Research 65 (2009), no. 2, 299-307, DOI 10.1016/j.jcsr.2008.02.004.

5 Paik J., Lee J., Jo Ko M, Ultimate shear strength of plate members with pit corrosion wastage, Thin-Walled Structures 42 (2004), no. 8, 1161-1176, DOI 10.1016/j.tws.2004.03.024.

6 Sadovsky Z, Drdacky M, Buckling of plate strip subjected to localised corrosion - a stochastic model, Thin-Walled Structures 39 (2001), no. 3, 247259, DOI 10.1016/ S0263-8231(00)00060-4.

7 Nakai T, Matsushita H, Yamamoto N, Arai H, Effect of pitting corrosion on local strength of hold frames of bulk carrier (1st report), Marine Structures 17 (2004), no. 5, 403-432, DOI 10.1016/ j.marstruc.2004.10.001.

8 Heinemeyer $\mathbf{C}$, Feldman $\mathbf{M}$, The influence of rivet corrosion on the durability of riveted connections, 6th European Conference on Steel and Composite Structures (Budapest, Hungary, August 2011), Proceedings of EUROSTEEL 20011 (Dunai L, Iványi M, Jármai K, Kovács N, Vigh L., eds.), ECCS European Convention for Constructional Steelwork, 2011, pp. 2217-2222.
9 Nakai T, Matsushita H, Yamamoto N, Arai H, Effect of pitting corrosion on local strength of hold frames of bulk carrier (2nd report)-Lateral - distortional buckling and local face buckling, Marine Structures 17 (2004), no. 8, 612-641, DOI 10.1016/ j.marstruc.2005.03.001.

10 Jakab G, Dunai L, Laboratory and virtual experiments on C-section compression members with semi-rigid connection, Periodica Polytechnica in Civil Engineering 54 (2010), no. 1, 31-43, DOI 10.3311/pp.ci.2010-1.04.

11 Oszvald K, Dunai L, Design buckling resistance of corroded members, determining the reduction factor for angle section elements, 6th European Conference on Steel and Composite Structures (Budapest, Hungary, August 2011), Proceedings of EUROSTEEL 20011 (Dunai L, Iványi M, Jármai K, Kovács N, Vigh L., eds.), ECCS European Convention for Constructional Steelwork, 2011, pp. 627-632. 